\title{
Anthropology and Education Business: Areas of Application, Approaches and Methodologies
}

\author{
Belete Mebratu \\ Medaille College
}

Yan Ma

Sun Yat-Sen University

The present study examines the convergence between anthropology and education business giving rise to the field of anthropology of education. The early works of Hewett, Boas and Montessori paved the way for the foundations of the application of anthropological contents and methods to the study and practices of educative processes and systems for better understanding and improvement of learning. School settings and classroom life provide relevant environment for anthropological inquiries. The application of anthropological contents and methods in various aspects of the study of education is significant. The business function of education in terms of the leadership and management of human, material and financial resources for optimal outcomes calls for anthropological insights and underpinnings in educational systems. Anthropological concepts and principles are applied in the areas of the foundations of education, curriculum development, culture studies, classroom interactions, multicultural education, business education, policy implementations, educational research and educational administration. Ethnographic methods have greatly contributed to the understanding of complex educational issues and challenges. Ethnographic methods of grounded theory, documentary content analysis, and action research are employed to study educational problems through the use of the techniques of purposive sampling, interview, observation, constant comparison, triangulations, key incident, narration, interpretive stance, and other tools of data gathering, interpretation and analysis.

\section{INTRODUCTION}

This paper is devoted to the study of the application of anthropology to education. The paper covers the historical development of the convergence of anthropology and education, areas of the applications of anthropological concepts, contents and methods to educational studies, and the anthropological approaches in the areas of educational research. In the study, attempts are made to show the contributions of both anthropologists and educators for the rise of a new field of anthropology of education since the early decades of the twentieth century. The paper also 
addresses the current practices in the applications of anthropology in education in the areas of teacher education, curriculum development, multicultural education, educational research, and in the overall application of anthropological methods in the study of life in classrooms in an educational setting in term of interactions, and the impacts of the classroom environment on learning.

Education is categorized as an industry by all the countries in the world. As an industry, education affects almost all of us - as students, parents, employees, employers, and citizens or as beneficiaries of scientific, medical, and technological research. As such, a college education is coming ever closer to being considered so basic that, like hospital care, it is too important to be left to the competitive forces of the marketplace. Today, as with many industries, education deals with numerous challenges brought about from internal and external pressures. These issues, such as the Global Economic Crisis, environmental and Greenhouse problems, burgeoning government legislation, and the public expectation of continuously improving service standards, affirm the need for the industry to adapt and to evolve. In fact, education entails business functions in various aspects, such as marketing the educational programs to students and their parents, recruiting highly qualified instructors, managing and controlling the operational cost. It involves systematic leadership and managerial operations of resources in order to achieve desirable outcomes based on set of standards at various levels. The present study, therefore, is based on the perspective that the application of anthropology in education is a subject of study for business anthropology (Weisbrod, Ballou, and Asch 2008).

Anthropology and education converged over common areas of interest in the understanding of humankind, cultures, changes, stability, child growth and development, and most importantly in the processes of education that influences the transition periods from childhood to adult life. The congruence on common denominators between anthropology and education was demonstrated during the early decades of the 20th century, and now the merge has grown to a full-fledged area of study with the title of educational anthropology. George Spindler is one of the authorities who formulated the foundations in the field of anthropology of education. According to Spindler, anthropology of education is concerned with "...intentional intervention in the learning process... with what children are learning at critical points throughout the entire development process" (p. 3, 1987). This takes the form of cultural transmission in a school setting and beyond.

Earlier in the first decade of the twentieth century, Edgar Hewett recommended in his writings broader anthropological perspectives in educational matters as in the area curriculum development. The work of Franz Boas in 1928 on the subject of maturation had relevance to the work of the school. As one of the earliest contributors to the rise of the application of anthropology to education, Boas showed, through his works in the 1930s and 1940s, that the growth and development of children are not determined by hereditary factors alone. Instead, he showed that environmental circumstances are crucial in the formation of the child's personality and therefore, educative processes should take into considerations the multitude of factors surrounding the child in and outside the school. Thus, educators need to take note of the cultural variables that interplay and act up on the child. In addition to the works of Hewett and Boas, the contributions of Maria Montessori, as one of the pioneers of educational anthropologist, laid the foundations for educational anthropology (Spindler, 2000).

The work and contributions of Maria Montessori during the first half of the $20^{\text {th }}$ century is a clear indication of the close tie between education and anthropology. Her works are among those earlier foundations for the field of educational anthropology. Maria Montessori sought the role of 
the interaction of the child with the total physical and human environment as a whole as the basis of learning. This was a new look into the process of education resembles the education of a child in a natural setting where education is life itself and life is the school. She used extensively ethnographic methods to observe, describe and explain children's activities and behaviors in their interactions with the total environment. By doing so, Montessori assumed the role of an educational anthropologist (Gearing, 1973).

The other major contributor to the convergence of anthropology and education is Ruth Benedict. The works of Benedict elaborated the functions of education in a society in terms of the transmissive, transitional, and transformative roles. The transmissive roles of education prepare the young for the expectations and responsibilities of a democratic society. In its transitional roles, education enables the youths to move into the adulthood period. And, education as a function of transformation can contribute to the changes and progresses in cultures. Melville Herskovits is another author who made major contribution to convergence of anthropology and education. His works have demonstrated that there is no such thing as racial inferiority or superiority as intelligence test does not necessarily measure innate behavior. His works have contributed in revealing the implicit prevalence of ethnocentricism in educational settings including in curricular materials and in teachers' behavior with the assumption of superiority of some cultures to other cultures (Nash, 1974).

Margaret Mead is a name that emerges as one of the influential authorities in the history of the convergence of anthropology and education. Her wirings emphasized that educators should provide with cultural characters congruent with the ideals of the Unite States that help children achieve stability of cultural heritage which is even more important at times of change. Her writings have illuminated on enculturation as a lifelong process, cultural transmission and the school (Gearing, 1973).

George Spindler, as a pioneer in the convergence of anthropology and education, has advocated the field of anthropology of education. His works showed the interconnected and interdependent set of educative system of the school in which teachers, students, and other school personnel are influenced by out-of-the school life experiences, and the impact of culture on the role of the teacher as a transmitter of culture. Theodore Brameld, an educational philosopher, has contributed to the convergence of anthropology and education. His contributions include in the areas of the applications of anthropology in teacher education programs of study. He argues that the application of anthropology in the education of teachers would help educators understand their cultures, conditions of change, and value systems that influence individual's behavior and actions (Nash, 1974). The establishment of the Council of Anthropology and Education in 1970, which became part of the American Anthropological Association, and numerous publications of papers on matters of anthropology and education have given impetus to the rise of the field of anthropology of education (Spindler, 1974).

As education began to embrace and promote diversities of learners of various forms, it broadened its areas of common interest with anthropology. Groups of students, parents, teaching faculty, staff, administrators, and other constituencies of the education systems became subjects of interest for the application of anthropological concepts and principles in education (D'Amato, 2010). The application of anthropology in education is further deemed important with an increasing interest in education in the understanding of classroom life with regard to student diversity in terms of race, ethnicity, gender, special needs and other forms that are becoming so vital factors for consideration in the planning and implementation of instruction based on the conditions and needs of the learners. These developments have long been part of the traditions of 
education, but became to the forefront of educational practices over the last four decades. With the rise of interest in matters of multicultural considerations in education in recent decades, the application of anthropological theories in education is becoming more vital in order to understand issues and problems in education in order to improve pedagogical best practices in classrooms.

\section{ANTHROPOLOGICAL APPLICATIONS IN EDUCATION}

\section{Multicultural Education}

Education is a function of the culture of a society in which it is practiced. The contents of the curriculum that are made available to the learners are selected from the culture of the larger society. Significant effort is made to make the contents of the curriculum as relevant and meaningful as possible to the experiences of the learners. Curriculum planners and policy makers are demonstrating commitments to draw as much bridge as possible between the home cultures and school cultures. The best use of anthropological tools and principles are essential to meet such goals of maintaining connections between what is happing in the classroom and the larger culture in the society. The application of educational anthropology in the study of groups and cultures inside and outside of the school helps to understand and formulate strategies to address issues of behavior problems, violence, school dropout and problems related to academic performances.

An important area for the application of anthropological subject matters in education lies in the ideals and principles of multicultural education. The review of literature in education reveals a significant shift over the last four decades in the emphasis given to the role of multicultural education in pluralistic societies. According to Banks (1995), multicultural education addresses the issues of cultural, ethnic, racial, gender and other differences, and the need to raise awareness and tolerance. By so doing, multicultural education enables students of diverse backgrounds develop positive attitudes across cultures. Gay (1994) remarks, similarly, that multicultural education is part of the desire to make cultural pluralism and ethnic diversity as the integral parts of educational processes. Thus, promoting children's sensitivity towards the plurality of ways of life is one of the objectives of multicultural education. Multicultural education also is viewed with reference to the promotion of the idea of human rights, social justice, and alternative life styles (Nieto, 1992).

The need for multicultural education is justified from various perspectives. Demographic factor is one. In a society of diverse groups, members of particular groups form and strengthen bonds within their groups, while creating distance toward others. This situation, in the long run, creates distrust, stereotypes, suspicion and fear towards the members of other groups. This can heighten tense relations and conflicts. Therefore, multicultural education is essential whereby school children learn about, and develop awareness and positive outlooks toward others (Sleeter, 1995). Multicultural education, it is believed, reduces biases, hostility, discrimination and the attribution of negative images about different groups as it provides information and knowledge about others (Gay, 1994).

From pedagogical point of view, multicultural education encourages better learning in the context of diverse students' background. Classroom experiences that are based on a single culture would favor some while excluding others. This results marginality, alienation, and isolation that would have some forms of impacts on classroom learning and beyond. This happens as the result of the discontinuity between the home culture of those marginalized and the 
culture that is valued in the school. For the good of the education of all students of diverse backgrounds, the school culture needs to be reflective of the diverse cultural backgrounds of all. This has to be the basis for the analysis of educational programs for the promotion of diversity in education, a role that is played by multicultural education (Spring 2000). There are also research reports that indicate the relationships between learning styles and ethnicity. That is, all people do not learn in the same way and learning style may be associated in some way with ethnicity (Hale-Benson, 1982; Shade, 1989). Instances of these are related to the formation of meanings, values given to competition, cooperation, and perception of the school, which can vary from one ethnic group to the other as well as within groups. In the contexts of diversities, thus, multicultural education advances responsive and adaptive educational practices to ethnic and other differences.

Multicultural education, further, provides the opportunity to meet the ideals of democracy in education. That is the principles of respect for the basic rights, freedom, equity and access to opportunities. Addressing the diverse needs in education is tantamount to respecting the ethnicity, linguistic, gender, religion, and the cultures of all. This constitutes respect for the rights and dignity of all. As multicultural education can contribute to this, it lays the foundations for civil and democratic society.

In terms of changes in the ways of life of society, multicultural education is prescriptive in content and trasformative in intent. The process of transformation involves, as Baptise (1979) explains, the institutionalization of the philosophy of cultural pluralism within the educational system. Cultural pluralism is one of the foundational principles of multicultural education. It envisions a society that affirms the democratic right of each ethnic group to retain its own heritage. Such a society is based on core values of equity and social justice, respect human dignity and universal human rights, and freedom to maintain one's language and culture (Bennett, 2001).

The theories of curriculum in relation to the nature of knowledge and the ways of knowing present multiple ways of learning and different forms of knowledge. From the multicultural education point of view, therefore, school curricula should reflect and facilitate a plurality of cultural learning styles, perspectives, experiences, contributions, and heritages. In this regard, Banks (1995) developed typology of knowledge that facilitates the process of multiculturalizing school curricula. What he refers as School Knowledge and Transfirmative Academic Knowledge are among the types of knowledge he forwards. School knowledge refers to what appears in textbooks, curricular guides, and other instructional materials, which are routinely used by classroom teacher. Whereas, the trasnforamtive academic knowledge includes concepts, paradigms, and explanations that challenge mainstream assumptions about knowledge. According to this perspective, knowledge is a social construction without being neutral. This type of knowledge provides alternative interpretation of ethnic, gender, and social groups' history, life, and culture and expands disciplinary canons to include cultural pluralism.

Specifically, Banks (1995) suggests an approach to multicultural curriculum reform that involves four levels. These are:

1. The Contribution Approach: - heroes, heroines, holidays, food, and discrete elements are celebrated occasionally.

2. The Additive Approach: - content, concepts, lessons, and units are added to the curriculum without changing its structure. 
3. The Transformative Approach: - the structure of the curriculum changes to enable students to view concepts, issues, events, and themes from the perspectives of diverse ethnic and cultural groups.

4. The Action Approach: - students make decisions on important personal, social, and civic problems and take actions to help solve them.

Taking a slightly different perspective, Sleeter and Grant (2003) identified five approaches of multicultural education that can address human diversity- race, ethnicity, gender, social class, and disability. These are:

1. Teaching the Exceptional and Culturally Different: - focuses on helping students of color, from low-income families, and with disabilities to succeed in schools and society.

2. Human Relations: - help students learn to appreciate each other's similarities and differences and to improve intercultural relations.

3. Single- Group Studies: - includes the study of groups that often are not addressed in the curriculum.

4. Multicultural Education: - a combination of the first three approaches, and suggest changes the school practices in such a way that human diversity become issues of central concern.

5. Education that is Multicultural and Social Reconstructionist: - addresses social inequalities in society. It is to prepare students to work actively to deal constructively with social problems, and to take charge of their own future.

Developments with regard to the growing importance attached to multicultural education in educational policy and practices has been supported and advanced by the applications and use of anthropological concepts and methodologies in education.

\section{Foundations of Education}

One of the specialties in the study of education is the area of the foundations of education. This area of study explores other fields of studies that can lend theories and concepts that can be used to the study of education. Spindler (2000) argues that anthropology as the study of humankind in the areas of culture, language, race, and evolution, is one area of the foundations of education. The processes of socialization, cross-cultural studies, cultural transmissions, child growth and adaptation, and intelligence are all common subjects of interest for anthropology and education. Change and stability, Spindler argues, are managed through what is being taught at school and at home, and this process draws common denominator between anthropology and education. Foundations of education, Spindler elaborates, is one of the central areas of studies in teacher education programs. Part of such studies draws so much contents and principles from the field of anthropology, specifically in the areas of the studies of cultures, values, the roles and functions of the school and that of the teacher in a society. Topics of social class, student teacher relationships and communications, group stereotypes, prejudice, and the notion of community in a school, and the social system in a school are domains of interest for study in educational anthropology.

The other important area of education where anthropological methods and contents are applied in education is the area of curriculum development. Curriculum planning principles require considerations to culture contents, human behavior and activities, and cultural values. Particularly, curriculum contents in the areas of social studies at elementary as well as higher 
levels draw their contents from anthropological subject matters. Such studies in teacher education programs by and large incorporate the contents and methodologies from the work of anthropology of education that draw the study of culture as foundations (Rosiek, 2006) Educational administration is another area of education of interest to the application of anthropology. In the preparation of educational administrators, the importance of cultural awareness, communications and interactions among teachers, parents and students, the roles of the leader in changes, cultural values, and the roles of the school in the community are relevant areas that need an application of anthropological understandings. These topics are part of the education of educational administrators (Wolcott, 1982).

Research in education uses so much of the anthropological tools and strategies. Studies in social class, community structures and educational opportunities, problems of adolescent, relationships between cultural differences and intelligence, socialization and education, and school organization are among some of those areas that call for the anthropological methods and concepts to better understand educative processes (Erickson, 1977; Wilcox, 1982). Interest in childhood education, elementary curriculum, school-community relationships, learning, cultural transmission, human nature, functions of education, child growth and development, values, acculturation, cultural normalcy, peer cultures, subcultures, enculturation form important areas of convergence between anthropology and education (Spindler, 1982).

One of the newly growing areas of application of anthropology in educational practices is in the area of business education. The humanistic and qualitative anthropological contents and methods are becoming relevant to the study business education in the area of consumer behavior. Ethnographic methods are be used to study human behavior from social and cultural perspectives of business. Such studies require to explore more into the cultural values of various groups and their consumption behavioral patterns, ethical matters, theories, methods of field work and data management tools. The application of anthropological concepts and methods contribute to improve curricular and instructional practices, and the quality of outcomes in business education (Tian, 2007; Tian \& Walle, 2009).

School is a social institution. The educative processes and the system set to run the process effectively create social dynamics and interactions. Cultures within the school and classroom settings define the workings of groups and individual. Such settings social and physical environments of the education field unequivocally invite anthropological quests. D'Amato (2006) explains that a classroom is the larger society in small scale. The learners engage in various forms of activities according to certain rules and expectations. Teachers with anthropological orientations understand the dynamics of the interactions and cooperation of the learners in a classroom setting. Under such circumstances differences, similarities, and interdependence are recognized and appreciated. The application of anthropological methods in educative processes in a classroom can enhance students' learning and performances.

\section{ANTHROPOLOGICAL APPROACHES IN EDUCATION}

\section{Ethnography and Its Application in Education}

Anthropological approaches in education involve extensive observation and description of behavior in order to understand what is happening. This most often takes place in a natural setting and is different from conducting experiments through a deliberate manipulation of variables. Ethnographic methods intend to look for answers to inquiries about cultural processes and changes across time (Wolcott, 2008). Ethnographic methods are good at understanding the 
cultures of a group, their organizations and their perceptions of their surroundings. The researcher would in the long run explores deep into their world and know their inner state of affairs (Carspecken \& Walford, 2001).

Ethnographic studies involve the process of inquiry. This is all about exploring what is happing at a setting in regard to the subject of study. The process requires to raise the question such as why this, not something else? This helps to see the relationships between the setting and the surrounding contexts. This can be enhanced through the use of theoretical frameworks that guide the observations. One of the first steps in ethnographic studies is to determine the focus of the study. The research should begin without specific categories, questionnaires or precise hypothesis. The researcher requires to use various techniques including maintaining relationship with the participants, the use of various tools of data collection, and remaining in the field for a long time. The process needs to be supported by body of knowledge to formulate the hypothesis, develop categories of observations, and to refocus and refine the process of the study (Wilcox, 1982).

Educational settings in classroom and schools are among those natural environments appropriate to carryout ethnographic studies (Wilcox, 1982). Ethnographic methods are of interest to educators in the areas of program evaluations, to see evidence of educational effects and accountability, students' performances and learning difficulties, and for the purpose of looking for areas for changes and reforms in the various aspects of the educational system. Such studies are also keenly required to make national studies in the areas of need diagnosis to identify common patterns and needs that can inform policy decisions. Evaluations in the form of formative or summative approaches can provide feedback that can be used to generate evidence to make decisions on important matters in regard of curriculum and other educational policy issues (Wolcott, 1982; Jeffry, 2004).

Ethnographic methods are used in the understanding of classroom life in term of interactions between the teacher and students, among the students, and between the students and the curriculum and the surrounding classroom environment. Anthropological studies can discern hidden as well as explicit messages conveyed in the classroom curriculum, biases, stereotypes, values, issues of equality, students' reactions to teachers' actions and behaviors, students' reception of the lessons and materials, and the classroom social dynamics and cultural patters (Gearing \& Epson, 1982). The use of ethnographic methods help us to identify and understand the interactions and tensions that occur among teachers, learners, principals, and parents in the processes of the implementations of curriculum and the coping strategies used to reach at resolutions. The appraisal of success or failures of policy implementations can also be carried out using ethnographic methods of inquiries (Jeffrey, (2004).

\section{Data Gathering and Analysis}

Ethnographic research undertaking requires various data gathering techniques and activities. The researcher can assume a role of non participant observer or a participant observer. The non participant observer tries to learn what is going on in a social setting without active involvement in the activities of the group in a setting. The participant observer, however, engages in various activities of the participants that are being studied. This gives the researcher the opportunity to have an inside look into the life of the group and enables one to write with greater level of trustworthiness. The findings of the study are based on the meanings the participants make of their situation that the researcher elicits inductively based on continuous and repeated 
interactions with the informants over long period of time (Tian, Lillis, and Van Marrewijk, 2010).

The sources of data for ethnographic studies are real life situations. The data are presented through descriptive language. In a school setting, ethnographic methods involve extensive recording of descriptive details of the conduct of everyday life using the techniques and tools of structured observation instruments, audiotapes, cameras, films, videotape, interviews and questionnaires, students' diaries, school documents such as cumulative records, samples of students' materials such as assignments, textbooks and other curricular materials. The ethnographer often assumes a non participants observer in the classroom setting, but also can be a participant observer by participating in the activities of the teaching and other faculty as in meetings, playgrounds and in cafeteria (Ogbu, 1974b; Peshkin, 1978; Hammond \& Spindler, 2006).

Ethnographic data are analyzed inductively which involves approaches that drive conclusions based on the study of particular circumstances. Thus, this is generating generalizations from the study of observation of specific circumstance. One of the techniques for data analysis is known as Key Incident approach. The Key Incident approach involves analysis of qualitative data surrounding an incident or event. The incident is linked to other incidents, phenomena, or theoretical constructs. It can be related and analyzed in relation to data generated from field notes, documents, demographic data, interviews and other sources of data. Another approach to data analysis is the quantification of qualitative data. This includes ranges of techniques from simple tallying of incidents to the use of other statistical methods (Erickson, 1977).

An ethnographic research is focused on specific investigation. The finding and conclusions of ethnographic fieldwork, therefore, are limited to the particular social setting of the study and do not intend to imply a wider generalizations. The findings of ethnographic studies are presented and interpreted in light of the perspectives of the participants of the study. In other words, the findings of such a study are the meanings the informants of the study make in relations to the subject of investigation. Anthropological approaches aim at answering questions about particular contexts based on the perspectives of a participant group about a subject of inquiry. Such studies rely on extensive fieldwork over a considerable amount of time. The studies use extensive descriptions and explanations (Walle, 2001; Baba, 2006). Instead of a single shot, the processes involve continuous analysis and interpretations. Ethnographic studies are validated with regard to believability in terms of design, strategies of data collection, and the participants that generate the data. Also, the theoretical stance that frames the study and the interpretation and analysis of the data in order to arrive at conclusions should be weighted for validity in terms of trustworthiness.

Purposing sampling is one of the methods of deterring the informants of the study who will participate in a study. In determining the participants, efforts should be made to get adequate representation so that relevant and appropriate data will be obtained that would enable the researcher to fully understand the subject of investigation. In the use of purposive sampling, the informants are identified and included in the study to seek answers to the question, "who is information rich?" to best understand the phenomenon under inquiry. Purposive sampling can also involve the technique called snowball sampling that is used to select participants whereby an informant suggests other resourceful informants for interview during the process of data collection (Seidman, 1998; Patton, 1990; Johnson \& Christensen, 2000; Creswell, 2002). 


\section{Grounded Theory}

Grounded theory is an inductive research approach that can be used in ethnographic studies to understand educational problems with the ultimate purpose of building theories or frameworks that would help explain a phenomenon. It is a systematic qualitative procedure used to generate a theory to explain a process, an action, or interaction about a substantive topic. It involves collecting data, coding, identifying categories or themes, connecting the categories, and forming a theory that can help to explain the process (Goetz \& LeCompte, 1984; Strauss \& Corbin, 1994; Johnson \& Christensen; 2000 Creswell, 2002).

With the framework of grounded theory, ethnographic studies utilize the techniques of thematic categorization based on discourse analysis and critical interpretative stance. The commonly recurrent patterns in the interview texts or field notes are identified and coded. Similar codes are then brought together to form themes. The themes are explanations and answers to the research questions of the study. Interconnecting themes of related frameworks are also formed to generate further abstractions and theories. The techniques of constant comparison and triangulation are used to validate the findings based on the interpretation and analysis of the data collected from the participants (Seidman, 1998; Creswell, 2002).

\section{Documentary Content Analysis}

Ethnographic studies in education can be based on research into the understandings and examinations of educational documents such as policies, curriculum, textbooks, pictures, and other form of communications. Documentary content analysis is one of those methods used to study educational documents to better understand meanings and messages conveyed by those documents. Documentary content analysis can be employed to analyze policy as well as curricular materials including textbooks. Content analysis is relevant to the study of educational documents like books to make inferences about their message (Gustafson, 1998). It is the method of drawing conclusions from text (Weber, 1990), involving procedures of the selection of the unit of analysis, category construction, sampling of contents, and coding the samples. Content analysis is used to reflect cultural patterns of groups, institutions, or societies and to reveal the focus of individuals, groups, institutions, or societal attention (Stemple \& Westley, 1981). The units of analysis include words, phrases, statements and illustrations in documents. Through the use of ethnographic method of documentary content analysis, educators as well as policy makers can learn about the contents and messages of educational materials with implications to group behaviors, biases, images, and stereotypes presented in the communications.

\section{Action Research}

Action research is one the methods of research that draws the tools of anthropology to better understand classroom life in an effort to improve teaching effectiveness and students' learning. The classroom teacher is the principal researcher in the application of action research. Thus, the teacher plays the role of a researcher. This empowers the teacher in identifying the problem and strategies used to carry out the research. Anthropological methods of observations, field notes, interviews, and documentary analysis can be part of the action research.

Action research is a type of applied research that contributes to the generation of principles and theories and is at the same time action - oriented. It is also a form of professional development. Action research involves an ethical commitment to improving society, improving ourselves and ultimately improving our lives together. Action research is essentially a cycle 
whereby research is performed, plans are developed and implemented and reflected upon (Holly, Arhar \& Kasten, 2005, p.31).

One of the conditions that call for the application of action research is when a teacher examines the needs of students and whether or not those needs are being met. Action research can enable the teacher identify the challenges of the students, learning difficulties, effectiveness of methods and techniques of instruction, and impacts of new curricular materials and applications of technology in the attainments of desirable goal and objectives. Action research, according to Holly, Arhar and Kasten (2005), is characterized by teachers' commitment for professional development based on continues reflective practices that involve ongoing observations, through collaboration with colleagues and beyond to the betterment of educational efforts and outcomes.

\section{SUMMARY AND CONCLUSION}

This paper is devoted to the exploration of the field of anthropology of education both from the historical perspective and current practices. The rise of the field of educational anthropology is traced back to the early years of the twentieth century. Earlier contributions by Hewett, Montessori, Boas and many more have laid down the foundation of educational anthropology. The establishment of the Association of Educational Anthropologists in 1970 and the numerous publications of materials have given impetus to the consolidation of the field of educational anthropology.

The application of anthropological contents and methods in various aspects of the study of education is significant. Anthropological concepts and principles are applied in the areas of the foundations of education, curriculum development, culture studies, classroom interactions, multicultural education, business education, policy implementations, educational research and educational administration. Ethnographic methods have greatly contributed to the understanding of complex educational issues and challenges. Ethnographic methods of grounded theory, documentary content analysis, and action research are employed to study educational problems through the use of the techniques of purposive sampling, interview, observation, constant comparison, triangulations, key incident, narration, interpretive stance, and other tools of data gathering, interpretation and analysis.

Policy formulation and implementations, curriculum development and practice, educational leadership and administration, teacher education, teacher student relationships, teacher parent relationships, and learning theories and principles need to be informed by and supported with anthropological principles, contents and methods in order to better understand educative processes and improve students' learning. It is important that the educational institutions treat the students and their parents as customers and respond to their desires instead of regarding them as meddlers. All schools must be run as businesses that try to satisfy their customers and make sure students get a good education.

This paper needs to be understood in light of its limitations in terms of its scope and depth. Some of the topics in the paper could have been examined in greater length. The paper attempts to highlight the overall historical developments and current practices in the emergence of anthropology of education thus opening the door for the study of education as a learning enterprise as well as a business function. Futures studies are important to examine the challenges of achieving quality education in the face of financial constraints, rising global competitions, and ever increasing demand to meet the needs of diverse groups. While there is an ever growing 
demand for quality system of education, on the other hand, the cost of education is becoming a challenge as much as providing access for all and narrowing down achievement gaps among learners of diverse backgrounds. The question of providing equal educational opportunities with the highest possible standards, producing qualified labor force required by the technology intensive market, and meeting the financial resources necessary to accomplish the desired goals are subjects of inquiries for the study of education in business anthropology. Thus, future researches are necessary to explore the kinds of leadership, relationships, classroom experiences, resources, teacher education, policies and school cultures that are critical to produce educated labor force critical for the constantly changing demands.

\section{REFERENCES}

Baba, M. (2006). Anthropology and business. In Encyclopedia of Anthropology, (pp. 87-117). James Birx (Ed). Thousand Oaks, CA: Saga Publications.

Banks, J. (1995). The historical reconstruction of knowledge about race: Implications for transformative teaching. Educational Researcher, 24(2), 15-25.

Bennett, C. (2001). Genres of research in multicultural education. Review of Educational Research, 71(2), 171-217.

Brameld, T. (1957). Cultural foundations of education, NY: Harper \& Row.

Carspecken, P. \& Walford, G. (2001). (Eds).Critical ethnography and education; Studies in educational ethnography, UK, London: An Imprint of Elservier Science.

Creswell, J.W. (2002). Educational research: Planning, conducting, and evaluating quantitative and qualitative research, NJ: Merrill Prentice Hall.

D'Amato, S. (2006). Anthropology and education (pp.778-787). In Encyclopedia of Anthropology, (Vol 2): James Birx. Thousand Oaks, CA: Saga Publications.

D'Amato, S.(2010). Anthropology and education (pp.874-882). In $21^{\text {st }}$ Century Anthropology: A Reference Handbook, (Vo.2) James Birx. Thousand Oaks, CA: Saga Publications.

Erickson, F. (1977). Some approaches to inquiry in school-community ethnography. CAE Newsletter, 8(2), 58-69.

Gay, G. (1994). A synthesis of scholarship in multicultural education.Urban Education Monograph Series, Center for Multicultural Education at the University of Washington Seattle.

Gearing, F. (1973). Anthropology and Education (pp. 1223-1249), In J. Honingmann (Ed). Handbook of Social and Cultural Anthropology, Chicago: Rand McNally College Publishing Company. 
Goetz, J.P., \& LeCompte, M.D. (1984). Ethnography and qualitative design in educational research, NY: Academic Press, Inc.

Gustafson, N. (1998). Content analysis in the history class. The Social Studies, 89, 29-34.

Hale-Bensen, E. (1982). Black children: Their roots, culture and learning styles. Baltimore, John Hopkins University Press.

Holly, M., Arhar, J., \& Kasten, W. (2005). Action research for teachers: Traveling the yellow brick road (2nd ed.), Upper Saddle River. NJ: Prentice-Hall.

Johnson, B., \& Christensen, L. (2000). Educational research: Quantitative and qualitative approaches, Boston: Allyn and Bacon.

Nash, R. (1974). The convergence of anthropology and education (pp. 5-25). In G. Spindler (Ed). Education and Cultural Processes toward an anthropology of education, NY: Holt, Rinehart and Winston, Inc.

Neito, C. (1992). Affirming diversity: The sociological context of multicultural education, White Plains, NY: Longman, Inc.

Ogbu, J. (1974b). Learning in Burgerside: An ethnography of education. In G. Foster \& R. Kemper (Eds). Anthropologists in Cities, Boston: Little, Brown, \& Com.

Patton, Q. (1990). Qualitative evaluation and research methods. (2 ${ }^{\text {nd }}$ edition), Newbury Park, CA: Sage.

Peshkin, A. (1978). Growing up American: Schooling and the survival of community, Chicago: University of Chicago Press.

Rosiek, J. (2006). Toward teacher education that takes the study of culture as foundations: Building bridges between teacher knowledge research and educational anthropology (pp.259285). In G. Spindler \& L. Hammond (Eds). Innovations in Educational Ethnography: Theory, Methods, and Results, Mahwah, NJ: Lawrence Erlbaum Associates Publishers.

Seidman, I. (1998). Interview as qualitative research: A guide for research in education and the social studies $\left(2^{\text {nd }} e d\right)$, NY: Teachers College Press.

Shade, J. (1989). Culture, style and the educative press. Springfield, III. : Charles C. Thomas.

Sleeter, E. (1995). An analysis of the techniques of multicultural education. In Banks, J. \& Banks, C. (Eds), Handbook of Research on Multicultural Education, NY: Macmillan Publishing.

Sleeter, E. \& Grant, A. (2003). Making choices for multicultural education: Five approaches to race, class, and gender, NY: John Wiley \& Sons. 
Spindler, G. (2000). Anthropology and education. In G. Spindler (Ed). Fifty years of anthropology and education 1950-2000,(pp.53-73). Mahwah: NJ. Lawrence Erlbaum Associates, Publishers.

Spindler, G. (1987). Education and cultural processes: Anthropological approaches, (2 ${ }^{\text {nd }}$ Edn). Prospect, IL: Waveland Press.

Spindler, G. (1982).(Ed). Doing the ethnography of schooling: An educational anthropology in action, NY: Holt, Rinehart and Winston.

Spindler, G. (1974). Educational and cultural processes to award an anthropology of education $(E d)$, NY: Holt, Rinehart and Winston, Inc.

Spring, J. (2000). American education ( $9^{\text {th }}$ ed.), NY: McGraw-Hill Company, Inc.

Stemple, G. \& Westley, B. (1981). Research methods in mass communications, Englewood Cliffs, NJ: Prentice- Hall Inc.

Strauss, A., \& Corbin, J. (1994). Grounded theory methodology: An overview: In N.K. Denzin \& Y.S. Lincolm (Eds.). Handbook of Qualitative Research, Thousand Oaks, CA: Sage.

Tian, R. (2007). From theory to practice: Anthropology in business education. In S. Demirdjian, T. Senguder, \& R. Tian (Eds.). Perspectives in consumer behavior: An anthropological approach, (pp. 12-28). Fort Worth, TX: Fellows Press of America.

Tian, R. \& Walle, A. (2009). Anthropology and business education: Practitioners application for qualitative method. International Journal of Management Education, 7(2), 59-67.

Tian, R, Lillis, M., \& Van Marrewijk, A. (2010). General Business Anthropology, Miami, FL: North American Business Press.

Walle, A. (2001). Qualitative research in intelligence and marketing, Westport, CT: Quorum Books.

Weber, P. (1990). Basic content analysis, (2 ${ }^{\text {nd }}$ ed.). Newbury Park, CA: Sage.

Weisbrod, B. A., J. P. Ballou, and E. A. Asch (2008). Mission and Money: Understanding the University, UK: Cambridge University Press.

Wilcox, K. (1982).Ethnography as a methodology and its application to the study of schooling: A review (pp.456-488). In G. Spindler (Ed). Doing Ethnography of Schooling: Educational Anthropology in Action, NY: Holt, Rinehart and Winston.

Wolcott, H. (1982). Mirrors, models, and monitors: Educator adaptations of ethnographic innovation (pp. 68-95). In G. Spindler (Ed). Doing Ethnography of Schooling: Educational Anthropology in Action, NY: Holt, Rinehart and Winston. 
Wolcott, H. (2009). Writing up qualitative research, Thousand Oaks, CA: Saga Publications, Inc. 